\title{
Sobre o outro em nós: intelectuais orgânicos, jovens e escola pública
}

About the other inside us: organic intellectuals, youth and public school

\author{
Bruna Carolina Silva dos Reis ${ }^{1}$ \\ Patrícia Leme de Oliveira Borba ${ }^{2}$ \\ Debora Galvani ${ }^{3}$
}

\section{Resumo}

Apresenta-se parte dos resultados de uma pesquisa, imbrincada em uma extensão universitária, ocorrida em uma escola técnica com estudantes secundaristas dedicados a refletir e compreender sobre a realidade vivida por pessoas em situação de rua durante um ano, instaurando processos contínuos de alteridade. Para tanto, foram utilizados diferentes recursos junto aos jovens e professores, como oficinas da diferença, debates com base em documentários e leituras, rodas de conversas com pessoa em situação de rua e profissionais da saúde e assistência social. Ao final do processo, evidenciou-se o envolvimento dos estudantes explicitado na produção artística e intelectual de sala-temática. Com base em questionários foi

\footnotetext{
1 Graduada em Serviço Social (2019) e Mestranda do Programa de Pós-Graduação em Serviço Social e Politicas Sociais (2019/2021) pela Universidade Federal de São Paulo, campus Baixada Santista.

${ }^{2}$ Graduação em Terapia Ocupacional pela Universidade Federal de São Carlos (2004), mestrado em Educação pela Universidade Federal de São Carlos (2008) e doutorado em Educação pela Universidade Federal de São Carlos (2012). Atualmente é professora adjunta IV da Universidade Federal de São Paulo no Departamento Saúde, Educação e Sociedade no Curso de Terapia Ocupacional e pós-doutoranda pelo Programa de Pós-Graduação em Terapia Ocupacional/CAPES/PNDP (2019/2020)

${ }^{3}$ Graduação em Terapia Ocupacional pela Universidade de São Paulo (1997) e mestrado em Ciências, pela Faculdade de Medicina USP (2008), doutorado em Ciências, pelo Instituto de Psicologia da USP (2015). Professora Adjunta da Universidade Federal de São Paulo, atualmente na Coordenadoria de Direitos Humanos da Pro-reitoria de Cultura e Extensão da UNIFESP.
}

Interfaces da Educ., Paranaíba, v.11, n.32, p. 412 - 431, 2020 
possivel dimensionar a mudança positiva de pensamentos e atitudes que os estudantes tiveram em relação ao tema, relacionada às categorias gramscianas de intelectual orgânico e catarse, a partir de uma compreensão de que o desenvolvimento do trabalho educativo-formativo ao longo do ano permitiu um reconhecimento dos jovens enquanto intelectuais orgânicos.

Palavra-chaves: Juventudes. Intelectual Orgânico. Educação. Situação de rua.

\section{Abstract}

Experience is presented in a technical school with high school students dedicated to reflect and understand about the reality lived by homeless people for a year. To this end, different resources were used with young people and teachers, such as workshops of difference, debates based on documentaries and readings, conversation with homeless people and health and social care professionals. At the end of the process, the student's involvement was evident in the artistic and intellectual production of the thematic room. Based on questionnaires it was possible to measure the positive change of thoughts and attitudes that students had regarding the theme, related to the gramscian categories of organic intellectual and catharsis, from an understanding that the development of educationaltraining work throughout the year has allowed young people to be recognized as organic intellectuals.

Key words: Youth; Organic Intellectual; Education; Homelless.

\section{Introdução}

A experiência que aqui será relatada é resultado da parceria entre um projeto de extensão da Universidade Federal de São Paulo, campus Baixada Santista, e a Escola Técnica Estadual Aristóteles Ferreira (ETECAF) da cidade de Santos, que se propôs a realizar projeto anual entre os alunos do 
ensino médio regular e ensino médio técnico - dos $1^{\circ}$ aos $3^{\circ}$ anos - nomeado "Sobre o outro em mim: Alteridade e Diversidade Cultural". Essa experiência compôs parte de uma pesquisa de iniciação científica ${ }^{1}$, imbrincada com atividades de extensão universitária, que pretendeu realizar um estudo sobre as trajetórias juvenis e a constituição de identidades balizadas pelos conceitos gramscianos de "intelectual orgânico" e "cartase" (GRAMSCI, 1991). Propõe-se, assim, relatar um recorte do todo vivido, focalizando as atividades que envolveram uma das salas do ensino médio, no caso do $2^{\circ}$ ano, em que a temática da alteridade pode ganhar existência nas reflexões sobre a realidade vivida por pessoas em situação de rua. Tal experiência revelou de maneira poética e inspiradora a possibilidade do trabalho com jovens nas escolas.

O "Juventudes e Funk na Baixada Santista: Território, Redes, Saúde e Educação" é um projeto de extensão da Universidade Federal de São Paulo, campus Baixada Santista, que se articula com o ensino e a pesquisa pretendendo ampliar os espaços formativos e de debate sobre temáticas pertinentes e que partem da experiência juvenil, sobretudo no que se referem ao exercício da sexualidade, estilos de vida e concepções de mundo junto a jovens moradores/as de regiões de vulnerabilidade social da Baixada Santista. O "Juventudes", como é conhecido, tem como um de seus pilares os pressupostos do educador Paulo Freire (1987), que se refletem em todas as propostas que envolvem prioritariamente jovens e territórios escolares, valorizando a formação de vínculos de confiança com seus parceiros jovens, professores e gestores -, a dialogicidade como ponto de partida e fim, além de um saber-fazer constantemente refletido e aprimorado, oferecendo repertório crítico para transformar a realidade desigual constituída a partir de enfeixamentos dos marcadores sociais da diferença (BRAH, 2006).

Nesse sentido, corrobora-se com Lopes et al. (2008) ao afirmarem que as práticas de extensão são fomento para a realização de pesquisas e

\footnotetext{
${ }_{1}^{1}$ Desenvolvida por meio do Programa Institucional de Bolsas de Iniciação Científica (PIBIC), edital $n^{\circ}$ XII/2017, agosto/2017 a julho/2018 renovado em edital $n^{\circ}$ XII/2018, agosto/2018 a julho/2019, intitulada "Trajetórias Juvenis e a Construção de Identidades de Intelectuais Orgânicos" sob supervisão da Prof ${ }^{a} \operatorname{Dr}^{a}$ Patricia Leme de Oliveira Borba.
}

Interfaces da Educ., Paranaíba, v.11, n.32, p. 412 - 431, 2020 
desenvolvimento de tecnologias sociais ao agregarem materiais que proporcionam a compreensão da realidade de maneira completa e das diversas possibilidades de intervenção baseada na convivência. Além disso, a atuação no espaço escolar tem permitido uma potente interlocução com diferentes atores, uma melhor apreensão da realidade com suas potencialidades e limitações, bem como, sobretudo, a constituição de fortes vínculos com os jovens que se constituirão, parte deles, como os sujeitos desta pesquisa.

Nesse sentido, faz-se necessário apontar que compreenderemos as juventudes enquanto uma categoria plural, partindo do pressuposto de que as condições históricas, culturais e sociais não se oferecem de maneira igual para todos. Deste modo, apreende-se que não se trata de uma experiência homogênea, ainda que se corrobore com a perspectiva de que a juventude, de forma genérica no âmbito da sociabilidade capitalista, "surja" enquanto um tempo acrescido de preparação para a complexidade das tarefas de produção e a sofisticação das relações sociais que a sociedade industrial trouxe (ABRAMO, 2005).

Partindo, portanto, do pressuposto da juventude como uma categoria plural e, assim, contextualizada a partir de juventudes, Guimarães (2009) irá afirmar que "o próprio discurso hegemônico que pensa a juventude como uma entidade universal já traz consigo uma forma de manipulação explícita dessa temática que oculta toda a diversidade e complexidade" (GUIMARÃES, 2009, p. 53), partilhando da reflexão de que, nomeado por ele, o "fenômeno da(s) juventude(s)" é revestido por uma dimensão histórica e sociocultural e de formas temporais e sociais de representar e vivenciar o que aqui denominamos como juventudes.

Assim, na relação com as juventudes da Baixada Santista, o projeto de extensão acima mencionado realiza ações no interior de escolas públicas dos municípios de Santos e Guarujá, dentre elas, abordaremos no presente relato a parceria com uma ETEC no desenvolvimento do projeto interdisciplinar "Espiral da Cidadania". Este projeto integra a atividade 
curricular da escola e tem como objetivo a integração dos estudantes a partir de um fluxo de atividades coletivamente elaboradas, propondo, efetivamente, contribuir com a formação de jovens atuantes e sensíveis às questões do seu tempo, constituindo identidades fortalecidas e ativas dos demais espaços de construção de cultura na cidade, para além da escola (ETECAF, 2013).

Dessa maneira, o "Juventudes" desde 2016 colabora com o projeto interdisciplinar, construindo de forma conjunta os temas anuais e participando - por meio das docentes coordenadoras ${ }^{2}$ e das graduandas extensionistas $^{3-}$ ativamente durante todo o ano através de diferentes estratégicas metodológicas - com estudantes secundaristas e professores para abordarem as temáticas elegidas no ano. Entre as estratégias destacam-se as oficinas da diferença (SILVA e BORBA, 2018), rodas de conversa e escuta ativa, fortalecendo processos da troca de aprendizados e saberes através da relação entre pares.

No ano de 2017 o tema anual escolhido foi "Diversidade Cultural e Alteridade - Sobre o outro em mim". Assim, cada sala dos três anos do ensino médio, totalizando 15 salas, acompanhou e aprofundou o campo de conhecimento em um grupo populacional/temática pré-definido. Realizou-se a seguinte subdivisão: o primeiro ano dedicou-se ao tema "ciclos de vida", sendo que cada uma das salas trabalhou os sub-temas a seguir: 1. crianças em situação de vulnerabilidade social; 2. adolescentes grávidos (pais e mães) ou pais jovens; 3 . jovens trabalhadores/as; 4 . adultos/as transexuais/travestis; 5. idosos/as institucionalizados/as. Já para o segundo ano a temática escolhida foi "grupos sociais estigmatizados", as salas se dividiram em: 1. comunidades indígenas; 2 . usuários/as de drogas; 3. pessoas em situação de rua; 4. mulheres com deficiência; 5. pessoas que vivem com HIV. Por fim, o terceiro ano trabalhou sobre "contextos de

\footnotetext{
2 Prof $^{a}$ Dr $^{a}$ Cristiane Gonçalves da Silva, professora do eixo inserção social da UNIFESP é a coordenadora do Projeto Juventudes e Funk e no ano de 2017 esteve afastada para realização do seu pós-doutorado, assim o trabalho foi coordenado pela $\operatorname{Prof}^{a}{ }^{\mathrm{a}} \mathrm{Dr}^{\mathrm{a}}$ Patricia Leme de Oliveira Borba em colaboração com as $\operatorname{Prof}^{a} \operatorname{Dr}^{\mathrm{a}}$ Debora Galvani e $\operatorname{Prof}^{\mathrm{a}} \operatorname{Dr}^{\mathrm{a}}$ Gabriela Vasters, as três pertencentes ao curso de Terapia Ocupacional da UNIFESP.

${ }^{3}$ Cerca de 20 alunos compõem a equipe de trabalho, sendo provenientes majoritariamente dos cursos de Serviço Social e Psicologia, em menor número de Terapia Ocupacional e Educação Física.
} 
mobilidade humana: crises, conflitos econômicos-políticos e desastres ambientais". Os sub-temas escolhidos para cada um das salas foram: 1 . latino-americanos; 2. senegaleses; 3. haitianos; 4. sírios e palestinos; 5. mexicanos nos Estados Unidos.

A temática da alteridade surge a partir da compreensão trazida por Velho (1996) de possibilidade de trocas entre pessoas/grupos nos mais diferentes níveis, refletindo acerca da questão de que para existirem trocas e encontros com um outro que é diferente de mim é necessário uma imersão e submersão em outra realidade com a qual não compartilho minha vivência. Corrobora-se, portanto, com Cardoso (2013) ao afirmar que:

\begin{abstract}
$(,,$,$) a alteridade parte do reconhecimento de nosso lugar humano,$ propiciando-nos compreender as diferenças como parte dessa humanidade. Ao identificar nossas similitudes podemos experienciar tais diferenças, respeitando-as independentemente de sentir o que o outro sente, acolhendo-as. Ao mesmo tempo, diante do reconhecimento de nossas similitudes, a experiência da alteridade nos impede de um posicionamento contra toda e qualquer forma de violação de nossa humanidade. (Cardoso, 2013, p. 60)
\end{abstract}

Assim, foi proposto que cada turma pudesse acompanhar e aprofundar o campo de conhecimento em um grupo populacional prédefinido, de maneira que o acompanhamento pôde ser feito a partir de diferentes dispositivos e estratégias: entrevistas/conversas presenciais e/ou virtuais com pessoas que experienciam determinada vivência e/ou técnicos e trabalhadores envolvidos na ação junto a esses grupos; diálogos com movimentos sociais; filmes e documentários sobre as temáticas relacionadas ao grupo; observações participantes em espaços públicos e/ou instituições que o público frequenta/participa e, também, leitura de textos bases para compreensão de uma dada realidade. Ao final desse processo as turmas teriam como produto final dos aprofundamentos a construção de uma sala temática a ser apresentada para visitação aberta a comunidade externa em um sábado letivo.

Nesta edição do projeto interdisciplinar, optou-se por um caminhar mais próximo e aprofundado, assim, foram direcionados uma extensionista e 
um professor da ETEC-AF para se tornarem "referências" do projeto em cada sala, estreitando os vínculos entre os pares extensionistas-secudaristas, como também aprofundando as relações já enraizadas das turmas com seus professores. Os temas foram sorteados, sendo que essa sala, em específico, recebeu a temática com entusiasmo, diferente de muitas salas que não responderam bem aos temas aos quais foram entregues. Tanto extensionistas como professoras tiveram oportunidade de escolher o tema, portanto, a sala que ficariam como referência. A escolha era motivada por diferentes razões, mas muito pelo fato de se sentirem mais seguros ou mais desafiados.

Nesse relato, abordaremos a sala do $2^{\circ}$ ano do ensino médio técnico que trabalhou com a temática dos grupos sociais estigmatizados com foco na população em situação de rua. No caso da estudante extensionista, a escolha por essa sala se deu pelo fato que naquele semestre estava realizando o estágio supervisionado em Serviço Social no Serviço de Abordagem Social ${ }^{4}$ da Secretaria de Assistência Social da Prefeitura de Santos.

No que se refere a este grupo social, Silva (2006) bem caracteriza o fenômeno da existência de pessoas em situação de rua ao afirmar que:

(...) pode-se dizer que o fenômeno população em situação de rua vincula-se à estrutura da sociedade capitalista e possui uma multiplicidade de fatores de natureza imediata que o determinam. $\mathrm{Na}$ contemporaneidade, constitui uma expressão radical da questão social, localiza-se nos grandes centros urbanos, sendo que as pessoas por ele atingidas são estigmatizadas e enfrentam o preconceito como marca do grau de dignidade e valor moral atribuído pela sociedade. É um fenômeno que tem caracteristicas gerais, porém possui particularidades vinculadas ao território em que se manifesta. No Brasil, essas particularidades são bem definidas. Há uma tendência à naturalização do fenômeno. (Silva, 2006, p.95)

Assim, é de suma importância destacar a realidade da cidade de Santos em relação à população em situação de rua. $O$ último Censo realizado no município conduzido pela FIPE (Fundação Instituto de

\footnotetext{
${ }^{4}$ O Serviço está presente na Política Nacional de Assistência Social (2004) e tipificado nacionalmente a partir da Tipificação Nacional dos Serviços Socioassistenciais (2014), tem como função desenvolver busca ativa de pessoas em situação de rua em vulnerabilidade ou risco social.
}

Interfaces da Educ., Paranaíba, v.11, n.32, p. 412 - 431, 2020 
Pesquisas Econômicas) registrou 591 pessoas em situação de rua e 206 acolhidas. Sobre o detalhamento do perfil da população na cidade: 94,9\% são adultos; $86,6 \%$ são homens; 40,8\% são pardos; 48,8\% possuem entre 31 e 49 anos; 72\% vieram de outras cidades; 64,9\% consomem álcool e 43,5\% declaram usar mais de uma substância psicoativa (FIPE, 2013). A complexidade da vida nas ruas é experimentada na cidade de diversas formas, gera sentimentos e ações antagônicas que vão da solidariedade à repulsa, do reconhecimento dos direitos à violência e negligência do próprio Estado.

Neste sentido, todos que participaram deste processo se envolveram com a complexidade das experiências do grupo social em questão. Tema escolhido ou sala escolhida pelo tema, segue a apresentação do processo de ensino-aprendizagem e de interlocução com a própria população em situação de rua a partir do caminho transcorrido pela turma do $2^{\circ}$ ano em conjunto com a professora e a extensionista.

\section{O caminho}

O processo de aproximação com as turmas se deu através de uma primeira atividade com as quinze salas da escola de maneira concomitante, no início do primeiro semestre de 2017, ocorrida em um sábado letivo. Foi apresentado o documentário "Por trás do Cartão Postal" (2016) que relata, a partir da narrativa de diversos sujeitos, as diferenças territoriais e socioeconômicas da cidade de Santos. A inquietação tomou conta da sala em toda aquela manhã, ocasionada pelas discussões que o disparador do vídeo causou no grupo: estudantes, professora e graduandas-extensionistas. O momento foi importante baliza de que aquela sala seria marcada pela inquietude do começo ao fim do projeto, reflexo da postura crítica do coletivo de estudantes e da professora orientadora, que naquele momento puderam aprofundar suas reflexões sobre os processos de exclusão e desigualdade nas cidades da Baixada Santista. 
A partir dessa primeira aproximação com a sala, foram apresentados à professora orientadora alguns materiais para subsidiar a construção coletiva de atividades com os jovens. Os materiais selecionados reuniam um conjunto de textos, normativas, dados estatísticos, vídeos, documentários e páginas em redes sociais. A troca entre professora e extensionista foi muito importante para a criação de vínculo e estabelecimento de confiança para o caminhar com a sala.

Com isso, foram propostos diferentes encontros com a turma para apresentação dos materiais, priorizando aqueles que dialogavam de forma mais direta e concreta com os jovens, sendo eles os vídeos, documentários e páginas em redes sociais. Esses materiais atuavam enquanto disparadores das discussões com os jovens e, a partir das discussões, foi possível introduzir os dados estatísticos, textos e normativas.

Inicialmente, as falas dos jovens em relação às pessoas em situação de rua eram muito marcadas pelo estigma das drogas e da saúde mental, traduzidos em "problemas de cabeça". O discurso, quase de maneira homogênea, apontava para uma individualização da questão, reproduzido em frases como "boas famílias orientam bem seus filhos", de maneira a justificar uma culpabilização dos sujeitos por estarem vivendo nas ruas. Nesse sentido, Serafino e Luz (2015) apontam que:

\footnotetext{
Em geral, a referência a este grupo social é carregada de preconceitos em relação a sua condição, as fragilidades dessas pessoas são vistas como as únicas causas da própria condição em que o viver na rua é considerado uma escolha individual, enquadrando-se em teorias que analisam esse fenômeno como sendo natural. (SERAFINO e LUZ, 2015, p. 76)
}

Para tanto, a sensibilização do grupo - com norte na alteridade - se deu a partir de vídeos e documentários disparadores que demonstrassem as trajetórias de vida, através da narrativa dos próprios sujeitos, de pessoas que vivem nas ruas, partindo do pressuposto de que a contrastação entre as diferentes vivências desses sujeitos e daqueles jovens permitiriam espaços de discussão mais abertos à escuta. O resultado dessa estratégia foi o interesse dos estudantes em ouvir mais relatos, mas agora presencialmente, de sujeitos que eles pudessem conhecer na vida real, sendo eles profissionais Interfaces da Educ., Paranaỉba, v.11, n.32, p. 412 - 431, 2020 
que atuam com essa população ou os próprios sujeitos que vivem nas ruas de Santos.

Assim, no início do segundo semestre, foi organizado o evento "Sobre o outro em mim: saberes em circulação" que envolvia todas as salas da escola - em um sábado letivo - para que alguns experts de cada temática pudessem conversar com os estudantes. Foram considerados e convidados experts nos assuntos pessoas que viviam aquela determinada situação definida no subtema, profissionais que atuam com os públicos eleitos e estudiosos das áreas. Neste sentido, coloca-se em cena uma pluralidade de saberes que necessitam ser reconhecidos, desconstruindo formas hegemônicas de hierarquia de saberes (FREIRE 1987).

Com isso, a sala que abordava o tema da população em situação de rua recebeu duas profissionais - uma enfermeira, Simone Jardim Aoki, e uma terapeuta ocupacional, Glenda Milek, - que atuam na equipe do Consultório na Rua de Santos (CNRua) ${ }^{5}$, A aproximação da sala com Simone e Glenda, que promovem uma intervenção direta com a população em situação de rua em Santos, permitiu que os estudantes realizassem um diálogo concreto com as questões que envolvem os direitos dessa população e a perspectiva defendida pelas profissionais, com base na Politica Nacional para a População em Situação de Rua (2009), de garantia de atendimento humanizado e universalizado, respeito à dignidade da pessoa humana e acesso amplo aos serviços e programas pertencentes às politicas públicas, no norte da igualdade e equidade. Esse encontro foi responsável por proporcionar aos estudantes uma relação ainda mais próxima com a temática e, de forma específica, com a temática na cidade de Santos, aproximando-nos, cada vez mais, da perspectiva da alteridade.

O próximo passo, respondendo à demanda levantada pelos estudantes, foi promover um encontro com uma pessoa que vive nas ruas. Fugindo do campo da mera curiosidade, eles estavam interessados em ouvir

\footnotetext{
5 Serviço de abordagem territorial que visa ampliar o acesso dessa população aos serviços de saúde, é assegurado pela Portaria $\mathrm{n}^{\circ}$ 122, de 25 de janeiro de 2012, do Ministério da Saúde. Interfaces da Educ., Paranaíba, v.11, n.32, p. 412 - 431, 2020
} 
presencialmente as histórias que tiveram contato apenas por vídeo, relatos das profissionais ou pelos encontros com a extensionista. O processo de afetar-se pela vivência do outro que não é igual a mim, mas que comigo compartilha a genericidade humana, já havia acontecido. A turma passou a buscar mais materiais para além daqueles que eram indicados pela extensionista, enxergar os sujeitos que estavam no caminho até a escola, conversar com eles, compreender as diversas questões que transpassam a vivência na rua, ultrapassar a cada dia as falas que individualizam e culpabilizam.

Assim, a partir dos vínculos que o estágio supervisionado proporcionaram à extensionista, promoveu-se um encontro entre Seu Jardim ${ }^{6}$, que vive em situação de rua há alguns anos e é usuário do Serviço de Abordagem Social; a assistente social Nayara Albino Gonçalves, supervisora de estágio da extensionista, e os estudantes. Aquela manhã, com certeza, foi o "divisor de águas" de todo o ano com a turma. O processo vivido foi muito importante, mas sem aquele encontro jamais chegaríamos a resultados tão bonitos como os que aqui pretendemos compartilhar.

Seu Jardim passou toda a manhã contando sua história de vida. Sem nenhuma intervenção da extensionista, de Nayara ou da professora orientadora. Apenas dos jovens. Houve perguntas, risadas, choros, sorrisos e no final muitos abraços. Um por um os estudantes fizeram uma fila para abraçar Seu Jardim e agradecer pelo encontro. Aquela manhã traduziu, na relação dos estudantes com Seu Jardim, as leituras todas que haviamos feito, enquanto Projeto de Extensão, sobre alteridade: reconhecer nas similitudes e diferenças com o outro - sua vivência e marcas que carrega - o que nos torna humanos.

Ao final do caminho que traçamos juntos a fim de traduzir em uma sala temática as afetações produzidas por esse processo com a temática da

\footnotetext{
${ }^{6}$ Decidiu-se por manter o nome real de todas/os que participaram do projeto, uma vez que eles/as assumiram o lugar e autoridade da fala e do conhecimento em relação à situação que compartilhavam. Deixar nomeado é dar autoria para quem compôs conosco e contribuiu para construir o que sem eles não seria possível nem inimaginável. Todos autorizaram e reiteraram nosso posicionamento.
}

Interfaces da Educ., Paranaíba, v.11, n.32, p. 412 - 431, 2020 
população de rua, os estudantes, junto da professora orientadora, ficaram responsáveis por apresentar em um sábado letivo a sala. Após algumas discussões sobre o conceito de alteridade ser algo para além do "sentir na pele" a vivência do outro - compreendendo essa impossibilidade diante das diferenças que nos separam - foram produzidas pequenas esquetes interpretadas pelos próprios estudantes.

A sala foi toda caracterizada com jornais, papelão e um ambiente escuro que a quem entrasse gerava uma sensação desagradável de sufocamento, incômodo e inquietação. Ali, sentados em cada canto da sala estavam os estudantes, declamando histórias da vida real que buscaram a partir da página "SP Invisivel"? A visita era guiada por um estudante que introduzia a experiência que estava por vir, alertando que as pessoas que ali estavam só compartilhariam suas histórias com quem, realmente, estava disposto a ouvi-las e notá-las.

Ao final, um estudante que se apresentava como "Jardim", recitava um poema escrito por um dos integrantes da turma:

\author{
Eu sou morador \\ E da onde? \\ Não é a pergunta. \\ Todas as manhãs me tiram de \\ onde estou \\ Dizendo: "Leve sua bagunça". \\ Acordo sem ter dormido, \\ Com os sentidos aguçados \\ Por conta do perigo. \\ O sentido do que sinto, \\ Ainda não encontrei. \\ Encontrei só mais um lugar \\ Que dá pra ficar, esperando a \\ chuva passar. \\ E junto com a chuva passa minha \\ vida, \\ O lado bom é que cada gota \\ Lava minhas feridas.
}

\footnotetext{
7 Organização de voluntários da cidade de São Paulo que divulga nas redes sociais por meio do Facebook, Instagram e página na web a história de vida de pessoas vivendo nas ruas da cidade (www.spinvisivel.org).

Interfaces da Educ., Paranaíba, v.11, n.32, p. 412 - 431, 2020
} 
Feridas no corpo e na alma Que às vezes me mantém vivo $\mathrm{E}$ que às vezes me tiram a calma. A calma que já não tenho Com certas impedâncias, Que levam as circunstâncias desagradáveis.

Não importa onde eu vá, Sempre estarei a incomodar. Tiraram tudo de mim: Minha família, meu lar. Só não pode me tirar o direito De ver a chuva passar, Visto apenas como um leigo na sociedade

Me falta integridade?

Ou lhe falta humanidade?

Onde eu moro?

Essa não é a pergunta. (Morador - William Sampaio)

O processo vivenciado pela sala de segundo ano, além de norteado pelo conceito de alteridade, constrói-se a partir da interpretação desses jovens enquanto intelectuais orgânicos, à luz de Gramsci. Jacinto (2017), ao explorar o conceito gramsciano, irá afirmar que "os intelectuais orgânicos atuam nos processos de formação de uma consciência crítica" (JACINTO, 2017, p. 87). Para apreender acerca da consciência critica a qual Jacinto se refere, faz-se necessário retomar o processo denominado por Gramsci (2000) de consciência da própria história. Segundo o autor, se um grupo social tem uma própria compreensão de mundo, aí está a libertação da reprodução dos valores, ideologias e força de trabalho em favor do grupo que é dominante. Com isso, o autor traz o conceito de "hegemonia", apreendido a partir da direção moral e política de uma classe que detém poder sobre todo o conjunto da sociedade.

A conceituação gramsciana de consciência da própria história e hegemonia é primordial na compreensão da categoria intelectual orgânico de maneira que os intelectuais se relacionam a esses processos incidindo diretamente sobre eles, já que irão fomentar o movimento de consciência na classe trabalhadora a partir de um caminho que Gramsci (1991) irá Interfaces da Educ., Paranaíba, v.11, n.32, p. 412 - 431, 2020 
determinar catarse, ou seja, a transformação da estrutura - até então naturalizada - em possibilidade de transformação, abrindo caminhos à liberdade como instrumento para criar uma nova reprodução das relações sociais, denominada pelo autor de contra-hegemonia.

A construção desses novos modos de pensar para produzir uma contra-hegemonia que suplante o senso-comum relaciona-se com nosso ponto de partida: a necessidade de que os indivíduos tenham consciência de sua própria história, ou seja, conheçam e reconheçam a realidade na qual estão inseridos de maneira que construam uma consciência e concepção de classe e realizem uma reflexão acerca de sua história e compreensão de mundo. Assim, entende-se que o intelectual orgânico corresponde àquele sujeito social que após passar pelo processo de catarse irá fomentar processos catárticos no coletivo de sua classe. É no terreno da cultura das classes subalternas que o intelectual encontra possibilidade de atuar e desenvolver um trabalho educativo-formativo com a classe a qual se identifica, na perspectiva de transformação social (SIMIONATTO, 2009).

A elaboração da exposição feita pelos jovens foi, inegavelmente, o ponto ápice do processo de desenvolvimento e compreensão crítica da realidade que abarca toda a complexidade que é estar nas ruas. Pode-se afirmar que eles e elas conseguiram unir diferentes linguagens artísticas para traduzir de modo muito sensivel e bonito todo o percurso que fizeram para chegar na sala-temática e, desta maneira, construíram uma estratégia com potencial para sensibilizar outras pessoas que participaram da exposição. Aponta-se nesse processo a intrínseca relação com o movimento catártico de Gramsci, superando o senso-comum no norte da consciência da história de sua classe e, além disso, proporcionando reflexão de outros sujeitos a partir de um trabalho educativo-formativo.

\section{Resultados}

Após a realização das salas temáticas, o projeto interdisciplinar tem como método avaliar com um questionário a perspectiva dos alunos em 
relação ao percurso realizado, de modo que eles possam se autoavaliar, avaliar a participação dos professores e equipe da extensão. Através da análise destes dados, a equipe gestora do projeto pode construir parâmetros que ajudem a implementar mudanças que correspondam e dialoguem com as expectativas dos jovens. No total obtivemos 26 respostas, correspondendo a $86 \%$ em uma sala com 30 alunos.

Em relação à avaliação da participação da turma quanto ao projeto, foi consenso que houve um grande envolvimento dos jovens, assim como avaliaram de modo muito satisfatório a participação da professora e satisfatório a participação da UNIFESP. Existiram três perguntas mais relacionadas ao que podemos considerar o "efeito" do Interdisciplinar em suas vidas. A primeira delas se refere à aprendizagem adquirida no projeto, questionando se poderia ter colaborado para o aprendizado de outras matérias.

Gráfico 1. Colaborou para o aprendizado de outras matérias

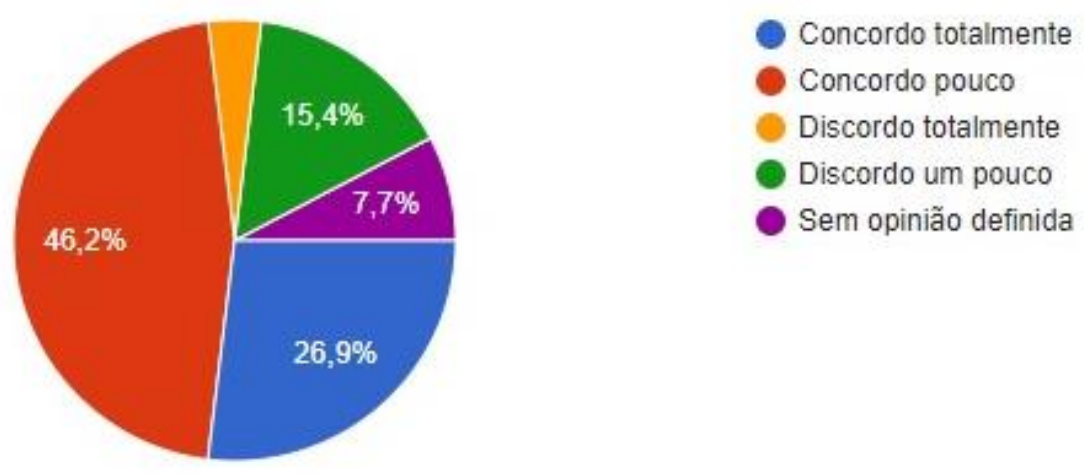

Fonte: Elaborado pelas autoras (2019).

Do total, $73 \%$ dos alunos reconhecem a interdisciplinariedade do projeto. Como se trata de um projeto com base muito assentada nas ciências humanas e a sala em questão é de ensino médio técnico de exatas, nos surpreende um aceno de interdisciplinariedade. 
No que se refere a auto avaliação, perguntamos se os estudantes perceberam mudança nos seus modos de pensar e atitudes em relação ao tema.

Gráfico 2. Mudei o modo como penso a temática abordada

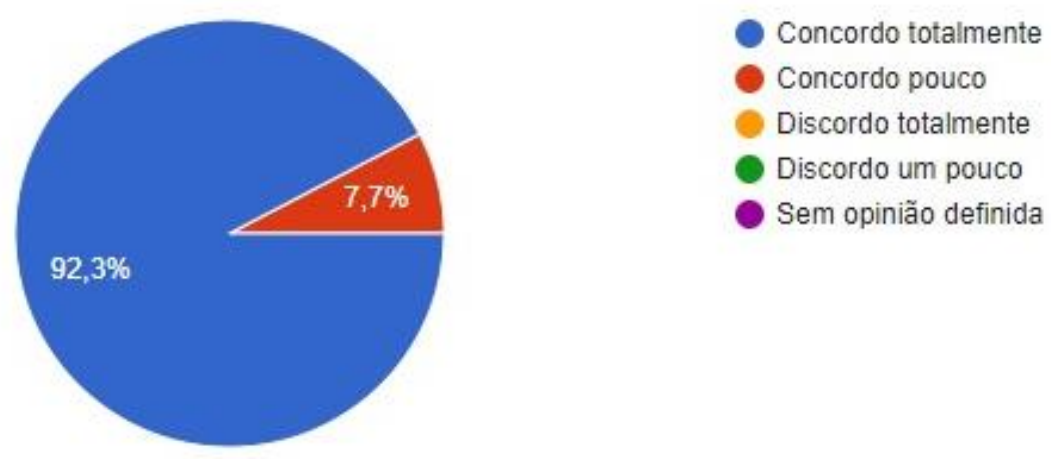

Fonte: Elaborado pelas autoras (2019).

Gráfico 3. Notei que houve mudanças nas minhas atitudes

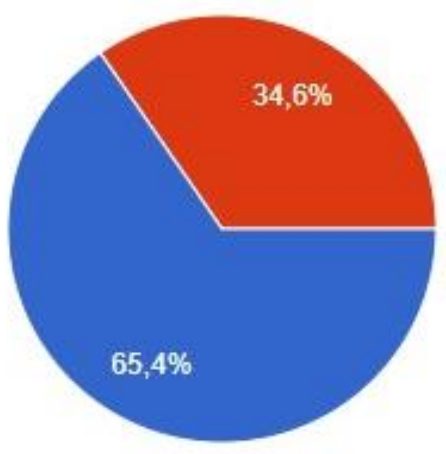

Fonte: Elaborado pelas autoras (2019).

Se analisarmos os dados a partir das falas aqui relatadas no primeiro encontro com os jovens, marcadas pelo estigma e pela individualização do fenômeno da vivência nas ruas, ressalta-se a importância da tradução dos dados para o cotidiano de vida desses jovens. Mattos e Ferreira (2004) apontam que o grupo ao qual chamamos "população de rua" tem sido alvo de discursos da mídia, representações religiosas, pesquisadores e coletivos organizados de pessoas com vivência nas ruas a fim de produzirem uma Interfaces da Educ., Paranaíba, v.11, n.32, p. 412 - 431, 2020 
representação a esse grupo social, entretanto muitas deles reforçando estigmas e discriminações acerca dessa população.

Dessa forma, a importância de produzir e reproduzir discursos críticos junto a esses jovens, que contribuam com o trabalho que vem sendo construído por movimentos sociais e coletivos organizados, reafirma que o projeto atingiu seus objetivos, corroborando para uma educação crítica, processual e dialógica. Em uma sociedade que invisibiliza e violenta as pessoas em situação de rua, é um enorme desafio formar jovens que respeitem e compreendam que há humanidade nas pessoas que compartilham dessa vivência. Não sabemos como isso irá refletir, mas já é um conjunto de experiências que irá marcar positivamente a trajetória reflexiva e atitudinal - desses jovens.

\section{Considerações Finais}

A “rua" e sua dinamicidade, seu tempo que ora é rápido e ora lento demais, bem como todo o processo vivenciado de maneira conjunta com a comunidade escolar, em específico com essa sala do $2^{\circ}$ ano, torna possível enxergar as "vitórias" cotidianas, as nossas micro-revoluções, com mais calor, mais valoração e mais esperança. O que não significa acreditar que a luta - no âmbito macrossocial - pelo acesso e não violação de direitos se naturaliza, se encerra ou diminui. Mas faz-se necessário acreditar na luta em suas pequenezas, que se tornam grandes vitórias.

É importante enaltecer a gestão escolar por apostar em colocar como pauta do cotidiano escolar temas polêmicos como os escolhidos nos subtemas do projeto, por provocar deslocamentos - concretos e subjetivos dos estudantes, dos professores e da equipe do projeto de extensão da Unifesp.

Ademais compreender que o êxito do projeto, dessa sala em específico, é a soma de ações que partem de diferentes sujeitos, mas notadamente: dos jovens que em suas buscas ativas ampliam seus mundos e repertórios de saber e ser; de uma professora que integra acertivamente o tema ao seu conteúdo curricular e de uma extensionista que ativa suas redes Interfaces da Educ., Paranaỉba, v.11, n.32, p. 412 - 431, 2020 
profissionais e pessoais para ampliar possibilidades de vivências e experiências de um grupo de jovens profundamente comprometidos com o projeto e com a temática proposta.

Esse conjunto de ações não poderia produzir outro resultado, senão uma sala temática envolta em arte, sensibilidade e profundidade crítica que sai do senso comum em direção ao questionamento da sociedade capitalista a qual produz e se reproduz com base na exclusão de uns muitos; sai do senso comum para tornar visível, com histórias e humanidade, aqueles para quem foi atribuída invisibilidade, culpabilização e desumanização, reforçando a reflexão acerca do processo gramsciano de catarse, ao qual guiou essa experiência enquanto pressuposto teórico.

Nesse sentido, aponta-se, a partir dessa perspectiva, para uma interpretação dos jovens dessa sala enquanto intelectuais orgânicos, compreendendo os processos vivenciados durante todo o ano - junto a extensionista e professora orientadora - enquanto parte do movimento de catarse, bem como a exposição da sala temática no bojo da cultura enquanto terreno - e terreno fértil - de desenvolvimento de trabalho educativoformativo com toda a comunidade escolar a fim de semear e florescer processos catárticos.

Ao relatar, parece simples empreender e deslocar tamanhos preconceitos e estigmas, fazer cada qual olhar para si e para um outro tão diferente de si com lentes de solidariedade e respeito. Isso só é possível com base em recursos e técnicas adequadas, com apoio humano, com disponibilidade de tempo para o diálogo e para a escuta. Estratégias "simples", contudo, fundamentais para esse processo com norte na transformação social - em direção à justiça e dignidade - e reconhecimento desses jovens enquanto intelectuais orgânicos, portanto promotores desse processo.

Por fim, para a Universidade, Escola e Educação - em sua acepção mais ampla - ficam a (re) aposta no legado freiriano, ou seja, nos processos 
de aprendizagem que se dão em parceria, com base nos saberes horizontais e entre pares, bem como na aliança entre teoria e prática.

\section{Referências}

ABRAMO, H.W. Condição juvenil no Brasil contemporâneo. In: ABRAMO, H.W.; BRANCO, P.P.M. (Orgs.). Retratos da juventude brasileira: análises de uma pesquisa nacional. São Paulo: Fundação Perseu Abramo, 2005. p. 37-72.

BRAH, A. Diferença, diversidade, diferenciação. Cadernos Pagu, n. 26, p. 329 a 376, jan-jun 2006.

CARDOSO, P. F. G. Ética e Projetos Profissionais: os diferentes caminhos do Serviço Social no Brasil. Campinas, SP: Papel Social, 2013.

ESCOLA TÉCNICA ESTADUAL ARISTÓTELES FERREIRA (ETECAF). Projeto Espiral da Cidadania, Santos, São Paulo, 2013.

FUNDAÇÃO INSTITUTO DE PESQUISAS ECONÔMICAS (FIPE), PREFEITURA MUNICIPAL DA CIDADE DE SÃO PAULO. Estimativa do Número de Pessoas em Situação de Rua da Cidade de Santos em 2013. São Paulo, 2013.

FREIRE, P. Paulo Freire \& educadores de rua: uma abordagem critica. Bogotá: Fundação Nações Unidas para a Infância, 1987.

GRAMSCI, A. Cadernos do cárcere. Rio de Janeiro: Civilização Brasileira, edição e tradução Carlos Nelson Coutinho; co-edição Luiz Sergio Henriques e Marco Aurélio Nogueira, v. 2, 2000.

A. Os intelectuais e a organização da cultura. Rio de Janeiro:

Civilização

Brasileira, edição e tradução Carlos Nelson Coutinho, v. 8, 1991.

GUIMARÃES, A. S. O Fenômeno da(s) juventude(s) a partir de um prisma sociológico: desafios teóricos e epistemológicos. Pró-discente: Caderno de Prod. Acad.-cient. Progr. Pós-grad. Educação, Vitória, v. 15, n. 2, p.52-60, ago/dez 2009. 
JACINTO, A. G. Trabalho socioeducativo no Serviço Social à luz de Gramsci: o intelectual orgânico. Revista Katálysis, Florianópolis, v. 20, n. 1, p. 77-85, jan/abr. 2017.

LOPES, R. E. et al. Juventude pobre, violência e cidadania. Saúde e Sociedade, v.17, n.3, p.63-76, 2008.

MATTOS, R. M.; FERREIRA, R. F. Quem vocês pensam que (elas) são? Representações sobre as pessoas em situação de rua. Psicologia e Sociedade, Porto Alegre. v. 16, n. 2, mai./ago. 2004.

SERAFINO, I.; LUZ, L. C. X. Políticas para a população adulta em situação de rua: questões para debate. Revista Katálysis, Florianópolis, v. 18, n. 1, p. 74-85, jan./jun. 2015.

SILVA, M. L. L. Mudanças recentes no mundo do trabalho e o fenômeno população em situação de rua no Brasil 1995-2005. 2006. 220 f.

Dissertação (Mestrado em Política Social) - Departamento de Serviço Social, Universidade de Brasília, Brasília, 2006.

SILVA, C. G.; BORBA, P. L. O. Encontros com a diferença na formação de profissionais de saúde: juventudes, sexualidades e gêneros na escola. Saúde e Sociedade, São Paulo, v. 27, n. 4, p. 1134-1146, 2018.

SIMIONATTO, I. Classes subalternas, lutas de classe e hegemonia: uma abordagem gramsciana. Revista Katálysis, Florianópolis: Edufsc, v. 12, n.1, p. 41-49, jan./jun. 2009.

VELHO, G. Violência, reciprocidade e desigualdade: uma perspectiva antropológica. In: VELHO, G. \& ALVITO, M. (orgs.), Violência e cidadania. Rio de Janeiro, Editora -UFRJ/Editora FGV. 1996. 